\title{
Studies on Antibacterial Activity and Diversity of Cultivable Actinobacteria Isolated from Mangrove Soil in Futian and Maoweihai of China
}

\author{
Feina Li, ${ }^{1}$ Shaowei Liu, ${ }^{1}$ Qinpei Lu, ${ }^{1}$ Hongyun Zheng, ${ }^{1,2}$ Ilya A. Osterman,,4 \\ Dmitry A. Lukyanov, ${ }^{3}$ Petr V. Sergiev, ${ }^{3,4}$ Olga A. Dontsova, ${ }^{3,4,5}$ Shuangshuang Liu, ${ }^{6}$ \\ Jingjing Ye, ${ }^{1,2}$ Dalin Huang $\mathbb{D}^{2},{ }^{2}$ and Chenghang Sun ${ }^{1}{ }^{1}$ \\ ${ }^{1}$ Institute of Medicinal Biotechnology, Chinese Academy of Medical Sciences \& Peking Union Medical College, Beijing 100050, China \\ ${ }^{2}$ College of Basic Medical Sciences, Guilin Medical University, Guilin 541004, China \\ ${ }^{3}$ Center of Life Sciences, Skolkovo Institute of Science and Technology, Moscow 143025, Russia \\ ${ }^{4}$ Department of Chemistry, A.N. Belozersky Institute of Physico-Chemical Biology, Lomonosov Moscow State University, \\ Moscow 119992, Russia \\ ${ }^{5}$ Shemyakin-Ovchinnikov Institute of Bioorganic Chemistry, The Russian Academy of Sciences, Moscow 117997, Russia \\ ${ }^{6}$ China Pharmaceutical University, Nanjing 210009, China
}

Correspondence should be addressed to Dalin Huang; huangdalin@glmc.edu.cn and Chenghang Sun; chenghangsun@hotmail.com

Received 29 March 2019; Accepted 21 May 2019; Published 9 June 2019

Guest Editor: Jayanta Kumar Patra

Copyright (C) 2019 Feina Li et al. This is an open access article distributed under the Creative Commons Attribution License, which permits unrestricted use, distribution, and reproduction in any medium, provided the original work is properly cited.

\begin{abstract}
Mangrove is a rich and underexploited ecosystem with great microbial diversity for discovery of novel and chemically diverse antimicrobial compounds. The goal of the study was to explore the pharmaceutical actinobacterial resources from mangrove soil and gain insight into the diversity and novelty of cultivable actinobacteria. Consequently, 10 mangrove soil samples were collected from Futian and Maoweihai of China, and the culture-dependent method was employed to obtain actinobacteria. A total of 539 cultivable actinobacteria were isolated and distributed in 39 genera affiliated to 18 families of 8 orders by comparison analysis of partial 16S rRNA gene sequences. The dominant genus was Streptomyces (16.0 \%), followed by Microbacterium (14.5\%), Agromyces (14.3\%), and Rhodococcus (11.9\%). Other 35 rare actinobacterial genera accounted for minor proportions. Notably, 11 strains showed relatively low 16S rRNA gene sequence similarities $(<98.65 \%)$ with validly described species. Based on genotypic analyses and phenotypic characteristics, 115 out of the 539 actinobacterial strains were chosen as representative strains to test their antibacterial activities against "ESKAPE" bacteria by agar well diffusion method and antibacterial mechanism by the double fluorescent protein reporter system. Fifty-four strains in 23 genera, including 2 potential new species, displayed antagonistic activity in antibacterial assay. Meanwhile, 5 strains in 3 genera exhibited inhibitory activity on protein biosynthesis due to ribosome stalling. These results demonstrate that cultivable actinobacteria from mangrove soil are potentially rich sources for discovery of new antibacterial metabolites and new actinobacterial taxa.
\end{abstract}

\section{Introduction}

Currently, antibiotic resistance is occurring more and more severely and already has become a global challenge to public health $[1,2]$; however, new types of antibacterial drugs are so extremely limited that clinicians are forced to the situation as "Bad bugs, No drugs." In early 2017, a request was made to the World Health Organization (WHO) by member states to develop a global priority pathogen list (PPL) of antibioticresistant bacteria to help in prioritising the research and development of new and effective antibiotic treatments $[3,4]$.

Actinobacteria, especially, the genus Streptomyces, are major producers of bioactive secondary metabolites $[5,6]$. After decades of screening, it has become increasingly difficult to discover new antibiotics from actinobacteria isolated from common soil environments. Nowadays, more and 
TABLE 1: Information of soil samples.

\begin{tabular}{|c|c|c|c|c|}
\hline Samples & $\begin{array}{l}\text { Sampling } \\
\text { sites }\end{array}$ & Location & The characteristic of soil & Sampling depth \\
\hline Sample 1 & Futian & $\begin{array}{l}22^{\circ} 31^{\prime} 45.82^{\prime \prime} \mathrm{N} \\
114^{\circ} 00^{\prime} 09.04^{\prime \prime} \mathrm{E}\end{array}$ & $\begin{array}{l}\text { Rhizosphere soil of } \\
\text { Aegiceras corniculatum }\end{array}$ & $5 \mathrm{~cm}$ under surface \\
\hline Sample 2 & Futian & $\begin{array}{l}22^{\circ} 31^{\prime} 45.79^{\prime \prime} \mathrm{N} \\
114^{\circ} 00^{\prime} 09.00^{\prime \prime} \mathrm{E}\end{array}$ & $\begin{array}{l}\text { Rhizosphere soil of } \\
\text { Aegiceras corniculatum }\end{array}$ & $5 \mathrm{~cm}$ under surface \\
\hline Sample 3 & Maoweihai & $\begin{array}{l}21^{\circ} 51^{\prime} 20.51^{\prime \prime} \mathrm{N} \\
108^{\circ} 36^{\prime} 14.11^{\prime \prime} \mathrm{E}\end{array}$ & Muddy soil & $10 \mathrm{~cm}$ under surface \\
\hline Sample 4 & Maoweihai & $\begin{array}{l}21^{\circ} 51^{\prime} 20.58^{\prime \prime} \mathrm{N} \\
108^{\circ} 36^{\prime} 14.12^{\prime \prime} \mathrm{E}\end{array}$ & $\begin{array}{l}\text { Rhizosphere soil of } \\
\text { Aegiceras corniculatum }\end{array}$ & $10 \mathrm{~cm}$ under surface \\
\hline Sample 5 & Maoweihai & $\begin{array}{l}21^{\circ} 44^{\prime} 35.73^{\prime \prime} \mathrm{N} \\
108^{\circ} 35^{\prime} 40.85^{\prime \prime} \mathrm{E}\end{array}$ & $\begin{array}{l}\text { Rhizosphere soil of } \\
\text { Aegiceras corniculatum }\end{array}$ & $10 \mathrm{~cm}$ under surface \\
\hline Sample 6 & Maoweihai & $\begin{array}{l}21^{\circ} 44^{\prime} 35.84^{\prime \prime} \mathrm{N} \\
108^{\circ} 35^{\prime} 40.87^{\prime \prime} \mathrm{E}\end{array}$ & Muddy soil & $10 \mathrm{~cm}$ under surface \\
\hline Sample 7 & Maoweihai & $\begin{array}{l}21^{\circ} 44^{\prime} 36.30^{\prime \prime} \mathrm{N} \\
108^{\circ} 35^{\prime} 40.93^{\prime \prime} \mathrm{E}\end{array}$ & Muddy soil & $10 \mathrm{~cm}$ under surface \\
\hline Sample 8 & Maoweihai & $\begin{array}{l}21^{\circ} 44^{\prime} 36.44^{\prime \prime} \mathrm{N} \\
108^{\circ} 35^{\prime} 40.82^{\prime \prime} \mathrm{E}\end{array}$ & Muddy soil & $10 \mathrm{~cm}$ under surface \\
\hline Sample 9 & Maoweihai & $\begin{array}{l}21^{\circ} 44^{\prime} 36.03^{\prime \prime} \mathrm{N} \\
108^{\circ} 35^{\prime} 40.69^{\prime \prime} \mathrm{E}\end{array}$ & Muddy soil & $10 \mathrm{~cm}$ under surface \\
\hline Sample 10 & Maoweihai & $\begin{array}{r}21^{\circ} 44^{\prime} 36.10^{\prime \prime} \mathrm{N} \\
108^{\circ} 35^{\prime} 40.50^{\prime \prime} \mathrm{E}\end{array}$ & Muddy soil & $10 \mathrm{~cm}$ under surface \\
\hline
\end{tabular}

more researches are focused on special habitats and extreme environments [7, 8], such as desert [9], marine [10], and mangrove [11], since microbes in special environments have to develop unique defense mechanism against the stress from their habitats and can evolve adaptive biosynthetic pathways for synthesizing novel biological compounds [12]. In fact, a large number of new bioactive compounds produced by actinobacterial strains residing in special environments have been discovered in recent years [13-15].

Mangrove is unique intertidal ecosystem with the condition of high moisture, high salinity, low oxygen, and high organic matter content $[16,17]$. Because the mangrove soil conditions are extremely different from common terrestrial conditions, microorganisms especially actinobacteria in mangrove soil have distinctive adaptation characteristics and have the potential to produce novel bioactive metabolites [18]. Investigations in many countries indicated that the mangrove actinobacteria have rich diversity and various biological activities $[6,13,16,19,20]$. At the time of writing, at least 86 new actinobacterial species including 8 novel genera have been isolated from mangrove. In addition, more than 84 new compounds produced by mangrove actinobacteria including some attractive structures such as salinosporamides, xiamycins, and novel indolocarbazoles [21, 22] have been reported. From north to south, mangroves in China mainly distribute along the southeast coast including Zhejiang province, Fujian province, Guangdong province, and Guangxi Zhuang Autonomous Region. Among them, Guangdong and Guangxi possess most of the mangrove area $[23,24]$.

In order to explore the antibacterial resources and gain insight into the diversity of cultivable actinobacteria, mangrove soil samples from Futian, Guangdong, and Maoweihai,
Guangxi, were collected and investigated. Due to the high prevalence of multidrug resistance among "ESKAPE" bacteria, defined by the Infectious Diseases Society of America as Enterococcus faecium, Staphylococcus aureus, Klebsiella pneumoniae, Acinetobacter baumannii, Pseudomonas aeruginosa, and Enterobacter spp., these pathogens in the global PPL of antibiotic-resistant bacteria were selected as the indicator bacteria in this study. In addition, a high-efficiency pDualrep2 reporter system was combined to accelerate the discovery of actinobacterial strains with clearly antibacterial mechanism from mangrove soil.

\section{Materials and Methods}

2.1. Collection of Mangrove Soil Sample. A total of ten soil samples were collected from 2 mangrove reserves of China in August, 2017. Two samples were collected from Futian, Shenzhen, Guangdong province and 8 from Maoweihai, Qinzhou, Guangxi Zhuang Autonomous Region. The information for the samples is listed in Table 1. All the samples were packed in sterilized envelopes and brought to the laboratory at the earliest possible time. Prior to grinding with mortar and pestle, each sample was immediately air-dried in the laminar flow hood at room temperature for 2 days.

2.2. Cultivable Actinobacteria Isolation and Maintenance. Ten media were prepared to isolate the actinobacterial strains (Table S1). All the isolation media were added $3 \%$ seawater. In addition, nalidixic acid (20 mg/L), cycloheximide $(50 \mathrm{mg} / \mathrm{L})$, and potassium dichromate $(50 \mathrm{mg} / \mathrm{L})$ were also added in the media to prevent the growth of Gram-negative bacteria and fungi. 
Actinobacteria were isolated by using dilution plating technique as described by Li et al. [25]. $0.2 \mathrm{~mL}$ of $10^{-2}$ soil suspension was spread onto isolation agar plates. After incubation at $28^{\circ} \mathrm{C}$ for $2-4$ weeks, colonies were picked up and streaked on the freshly prepared YIM 38 medium (1 L sterile water: $4.0 \mathrm{~g}$ glucose, $4.0 \mathrm{~g}$ yeast extract powder, $5.0 \mathrm{~g}$ malt extract powder, $15.0 \mathrm{~g}$ agar, $\mathrm{pH}$ 6.0) to obtain the pure isolates. The pure cultures were maintained on YIM 38 agar slants at $4^{\circ} \mathrm{C}$ for several weeks and also preserved in glycerol suspensions $(20 \%, \mathrm{v} / \mathrm{v})$ at $-80^{\circ} \mathrm{C}$.

\subsection{PCR Amplification and Sequencing of $16 S$ rRNA Gene.} Genomic DNA was extracted as described by Li et al. [26] and used as the template to amplify the 16S rRNA gene by PCR with the primers 27F ( $5^{\prime}$-AGAGTTTGATCCTGGCTCAG$\left.3^{\prime}\right)$ and 1492R ( $5^{\prime}$-GGTTACCTTGTTACGACTT-3 ${ }^{\prime}$ ) [27]. The reaction mixture $(50 \mu \mathrm{L})$ contained $25 \mu \mathrm{L} 2 \times$ supermix (TransGen, Beijing), $1 \mu \mathrm{L}$ each of the primers ( $10 \mathrm{mM}$, Sangon Biotech, Beijing), $1.5 \mu \mathrm{L}$ DNA, and $21.5 \mu \mathrm{L} \mathrm{ddH}_{2} \mathrm{O}$. The PCR amplification included the following parameters: (i) $95^{\circ} \mathrm{C}$ for $3 \mathrm{~min}$ (initial denaturation), (ii) 30 cycles of $94^{\circ} \mathrm{C}$ for $1 \mathrm{~min}$ (denaturation), $60^{\circ} \mathrm{C}$ for $1 \mathrm{~min}$ (annealing), and $72^{\circ} \mathrm{C}$ for $1 \mathrm{~min}$ (extension), and (iii) $72^{\circ} \mathrm{C}$ for $10 \mathrm{~min}$ (final extension). The amplicons were then visualized by gel electrophoresis using 5 $\mu \mathrm{L}$ of PCR product in a $1 \%$ agarose gel. The PCR products were purified and then sequenced on the ABI PRISM ${ }^{\mathrm{TM}}$ 3730XL DNA Analyzer (Foster City, CA).

2.4. Sequence Analysis. The 16S rRNA gene sequences obtained were compared with those of the type strains available in NCBI (http://www.ncbi.nlm.nih.gov/) and the EzBioCloud (https://www.ezbiocloud.net/) [28] using the Basic Local Alignment Search Tool (BLAST) [29] to determine an approximate phylogenetic affiliation of each strain. The corresponding sequences of closely related type species were retrieved from GenBank database using the EzBioCloud server. Multiple alignments were made using CLUSTAL_X tool in MEGA version 7.0 [30]. Phylogenetic tree based on neighbour-joining method [31] was constructed using the MEGA version 7.0. Evolutionary distances were calculated using the Kimura's two-parameter model [32]. The topology of the phylogenetic tree was evaluated by bootstrap method with 1000 replications [33].

2.5. Nucleotide Sequence Accession Numbers. The sequences obtained in this study were deposited in GenBank with the $16 \mathrm{~S}$ rRNA gene sequences under the accession numbers: MK589722 -MK589799 and MK685120.

2.6. Small-Scale Fermentation. To check the antibacterial potential of isolated actinobacterial strains, small-scale fermentation was performed. One hundred and fifteen representative strains were selected based on analyses of partial $16 \mathrm{~S}$ rRNA gene sequences and phenotypic characteristics. Each strain was inoculated separately in six of $500 \mathrm{ml}$ Erlenmeyer flasks containing $100 \mathrm{ml}$ of YIM 38 broth medium. After being incubated for 7 days at $28^{\circ} \mathrm{C}$ with shaking (at 180 $\mathrm{rpm}$ ), the $600 \mathrm{ml}$ fermentation broth was centrifuged and its supernatant was extracted twice with ethyl acetate (EtOAc, $1: 1, \mathrm{v} / \mathrm{v})$. Organic layer was dried up by rotary evaporation, and residue was dissolved in $3 \mathrm{ml}$ of methanol. Sixty milliliter of water layer was lyophilized, and then its residue was dissolved in $3 \mathrm{ml}$ of $50 \%$ methanol-water. The mycelium was soaked overnight in acetone and then filtered. The acetone extract was dried in vacuo and dissolved in $3 \mathrm{ml}$ of $50 \%$ methanol-water. Ultimately, each strain has three kinds of sample for antibacterial assay.

2.7. Antibacterial Screening. Six sets of indicator bacteria were used in antibacterial assay. Each set consisted of two strains, one was sensitive strain and another was drugresistant strain. The indicator bacteria were Enterococcus faecalis (E. faecalis, ATCC 33186, 310682), Staphylococcus aureus (S. aureus, ATCC 29213, ATCC 33591), Klebsiella pneumoniae (K. pneumoniae, ATCC 10031, ATCC 700603), Acinetobacter baumannii (A. baumannii, 2799, ATCC 19606), Pseudomonas aeruginosa (P. aeruginosa, ATCC 27853, 2774), and Escherichia coli (E. coli, ATCC 25922, ATCC 35218). E. faecalis 310682, A. baumannii ATCC 19606, and E. coli ATCC 35218 are resistant to vancomycin, carbapenems, and ampicillin, respectively. S. aureus ATCC 33591 is resistant to both cefoxitin and oxacillin. Both K. pneumoniae ATCC 700603 and $P$. aeruginosa 2774 are resistant to aminoglycosides; meanwhile, K. pneumoniae ATCC 700603 is resistant to $\beta$-lactam antibiotics and $P$. aeruginosa 2774 is resistant to carbapenems. Indicator bacteria were obtained either from American Type Culture Collection (ATCC) or from the clinic and deposited in Institute of Medicinal Biotechnology, Chinese Academy of Medical Sciences.

Antibacterial assay was performed using agar well diffusion method [34]. After drying up, paper disk (diameter $6 \mathrm{~mm}$ with $60 \mu \mathrm{L}$ prepared sample) was placed on Mueller-Hinton $(\mathrm{MH})$ agar containing the indicator bacteria. Meanwhile, $60 \mu \mathrm{L}$ methanol without sample and with $1 \mu \mathrm{g}$ levofloxacin was used as the negative control and positive control, respectively. The plates were incubated at $37^{\circ} \mathrm{C}$ for 24 $\mathrm{h}$, and the antibacterial activity was evaluated by measuring the inhibition zone.

2.8. Mechanism of Action Determination. Ribosome and DNA biosynthesis inhibitors were screened by the double fluorescent protein reporter system with reporter strain JW5503-pDualrep2 [35]. Briefly, $100 \mu \mathrm{L}$ of ethyl acetate extract was dried up in laboratory hood and $100 \mu \mathrm{L}$ DMSO was added as sample to be tested. $2 \mu \mathrm{L}$ of sample was applied to agar plate containing a lawn of the reporter strain. After overnight incubation at $37^{\circ} \mathrm{C}$, the plate was scanned by ChemiDoc (Bio-Rad) system with two channels including "Cy3-blot" (553/574 nm, green pseudocolor) for RFP fluorescence and "Cy5-blot" (588/633 nm, red pseudocolor) for Katushka2S fluorescence. Induction of Katushka2S expression is triggered by translation inhibitors, while RFP is upregulated by induction of DNA damage SOS response. Levofloxacin and erythromycin were used as positive controls for DNA biosynthesis and ribosome inhibitors, respectively. 
TABLE 2: Information on genera distribution of actinobacterial strains.

\begin{tabular}{|c|c|c|c|}
\hline Genera & No. of isolates & No. of strains for assay & No. of strains with antibacterial activity \\
\hline Streptomyces & 86 & 27 & 20 \\
\hline Microbacterium & 78 & 6 & 0 \\
\hline Agromyces & 77 & 5 & 2 \\
\hline Rhodococcus & 64 & 6 & 4 \\
\hline Sinomonas & 46 & 5 & 3 \\
\hline Mycobacterium & 28 & 3 & 0 \\
\hline Curtobacterium & 23 & 2 & 0 \\
\hline Nocardia & 20 & 7 & 2 \\
\hline Arthrobacter & 15 & 3 & 1 \\
\hline Leifsonia & 13 & 4 & 1 \\
\hline Paenarthrobacter & 11 & 1 & 1 \\
\hline Kocuria & 10 & 5 & 1 \\
\hline Nocardiopsis & 7 & 4 & 3 \\
\hline Brachybacterium & 7 & 1 & 0 \\
\hline Agrococcus & 6 & 2 & 0 \\
\hline Glutamicibacter & 6 & 2 & 1 \\
\hline Kitasatospora & 5 & 1 & 1 \\
\hline Isoptericola & 4 & 1 & 1 \\
\hline Mycolicibacterium & 4 & 4 & 2 \\
\hline Aeromicrobium & 3 & 1 & 0 \\
\hline Brevibacterium & 2 & 1 & 0 \\
\hline Schumannella & 2 & 2 & 0 \\
\hline Micrococcus & 2 & 2 & 1 \\
\hline Arsenicicoccus & 2 & 2 & 0 \\
\hline Cellulosimicrobium & 2 & 2 & 1 \\
\hline Gordonia & 2 & 2 & 2 \\
\hline Micromonospora & 2 & 2 & 2 \\
\hline Pseudarthrobacter & 1 & 1 & 1 \\
\hline Homoserinibacter & 1 & 1 & 1 \\
\hline Amnibacterium & 1 & 1 & 1 \\
\hline Frigoribacterium & 1 & 1 & 0 \\
\hline Oerskovia & 1 & 1 & 0 \\
\hline Janibacter & 1 & 1 & 0 \\
\hline Streptosporangium & 1 & 1 & 0 \\
\hline Actinomadura & 1 & 1 & 1 \\
\hline Modestobacter & 1 & 1 & 0 \\
\hline Pseudonocardia & 1 & 1 & 1 \\
\hline Nocardioides & 1 & 1 & 0 \\
\hline Microlunatus & 1 & 1 & 0 \\
\hline Total number & 539 & 115 & 54 \\
\hline
\end{tabular}

\section{Result}

3.1. Isolation and Diversity of Cultivable Actinobacteria from Mangrove Soil. Among 843 isolates obtained, 539 isolates were identified as actinobacterial strains by partial 16S rRNA gene sequence comparison analysis and further assigned to 39 genera in 18 families of 8 orders as follows: Streptomyces, Microbacterium, Agromyces, Rhodococcus, Sinomonas, Mycobac-terium, Curtobacterium, Arthrobacter, Nocardia, Kocuria, Paenarthrobacter, Nocardiopsis, Glutamicibacter, Brachybacterium, Agrococcus, Isoptericola, Aeromicrobium,
Kitasatospora, Mycolicibacterium, Micrococcus, Arsenicicoccus, Brevibacterium, Schumannella, Leifsonia, Cellulosimicrobium, Gordonia, Micromonospora, Homoserinibacter, Pseudarthrobacter, Amnibacterium, Frigoribacterium, Oerskovia, Janibacter, Streptosporangium, Actinomadura, Modestobacter, Pseudonocardia, Nocardioides, and Microlunatus (Figure 1). The predominant genus was Streptomyces (16.0\%, 86 strains), followed by Microbacterium (14.5\%, 78 strains), Agromyces (14.3\%, 77 strains), and Rhodococcus (11.9\%, 64 strains) (Table 2). 


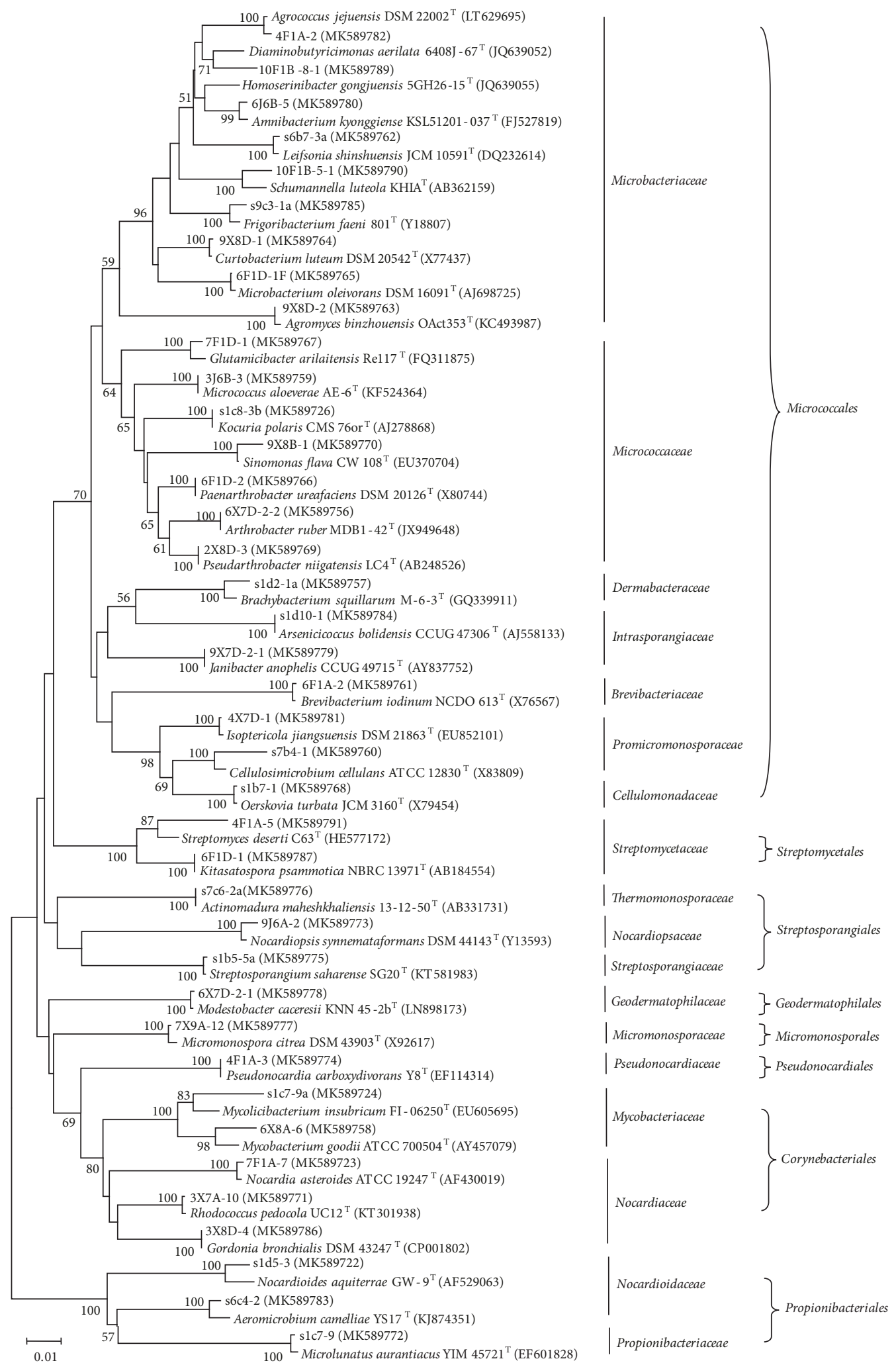

Figure 1: Phylogenetic tree based on the 16S rRNA gene sequences using neighbour-joining method for the representative actinobacterial strains and their closely related type strains. Numbers at nodes indicate the level of bootstrap support based on 1000 replications (only values $>50 \%$ are shown). Bar, $1 \mathrm{nt}$ substitutions per $100 \mathrm{nt}$. 


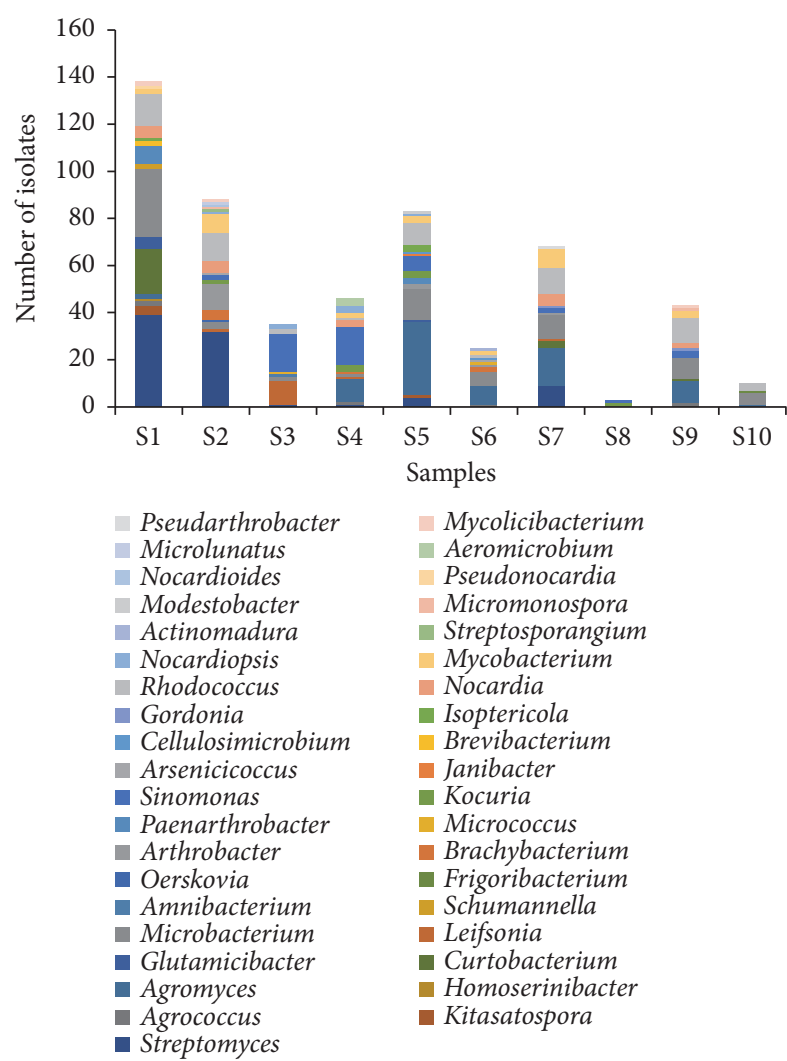

(a)

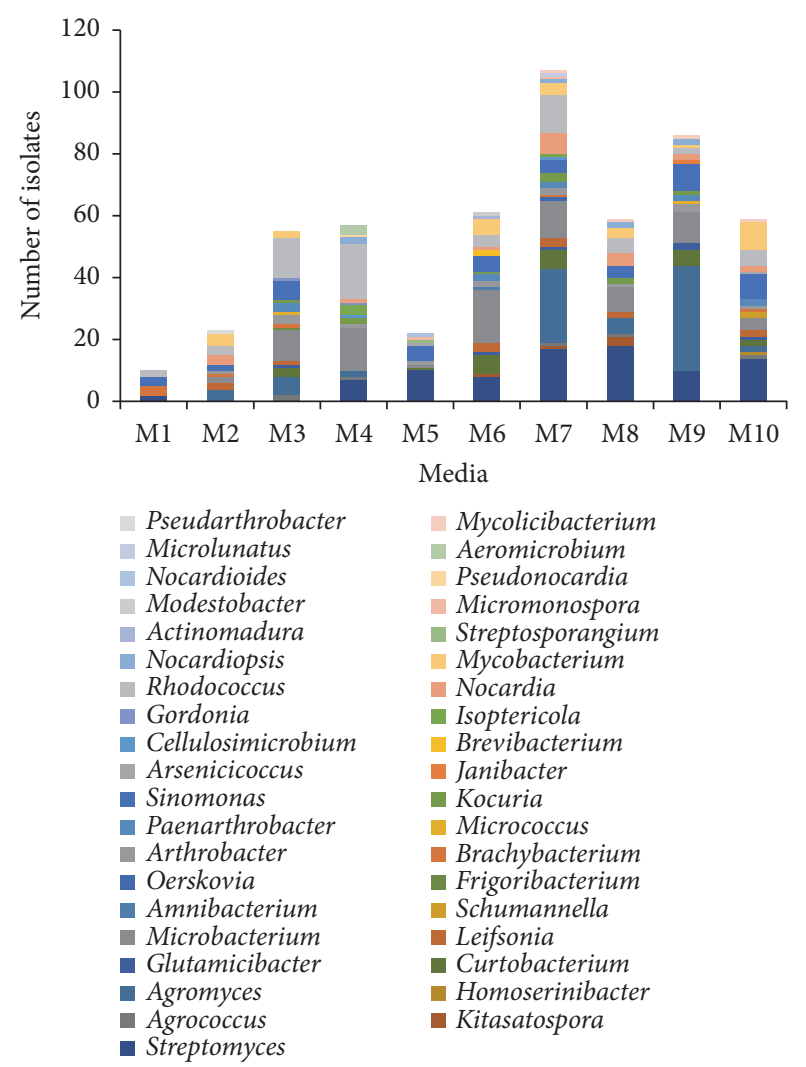

(b)

FiguRE 2: Diversity of cultivable actinobacteria from mangrove soil in Futian and Maoweihai. (a) Number of actinobacterial isolates from different samples. (b) Number of actinobacterial isolates recovered from the different culture media.

TABLE 3: The sequence analyses based on almost full-length $16 \mathrm{~S}$ rRNA gene (> $1321 \mathrm{bp}$ ) of 11 potential new species.

\begin{tabular}{|c|c|c|c|}
\hline Strain & Accession number & Closest type species & Similarity of 16S rRNA gene sequence \\
\hline 9X7D-4 & MK589797 & Agromyces brachium IFO $16238^{\mathrm{T}}$ & $98.1 \%$ \\
\hline $2 \mathrm{X} 8 \mathrm{D}-4$ & MK589796 & Agromyces neolithicus $23-23^{\mathrm{T}}$ & $98.1 \%$ \\
\hline $9 \times 9 A-10$ & MK589795 & Agromyces luteolus IFO $16235^{\mathrm{T}}$ & $98.4 \%$ \\
\hline s7b8-3 & MK589792 & Agromyces italicus DSM $16388^{\mathrm{T}}$ & $98.2 \%$ \\
\hline s6c9-2a & MK589794 & Agromyces binzhouensis OAct $353^{\mathrm{T}}$ & $98.3 \%$ \\
\hline s6c8-3a & MK589793 & Agromyces binzhouensis OAct $353^{\mathrm{T}}$ & $98.4 \%$, \\
\hline 7X8A-10 & MK589799 & Agromyces tropicus CM9-9 $9^{\mathrm{T}}$ & $98.3 \%$ \\
\hline 7X7D-2 & MK589798 & Agromyces tropicus $\mathrm{CM} 9-9^{\mathrm{T}}$ & $97.2 \%$ \\
\hline 10F1B-8-1 & MK589789 & Homoserinibacter gongjuensis $5 \mathrm{GH} 26-15^{\mathrm{T}}$ & $97.7 \%$ \\
\hline 10F1B-5-1 & MK589790 & Schumannella luteola $\mathrm{KHIA}^{\mathrm{T}}$ & $98.2 \%$ \\
\hline 4F1A-5 & MK589791 & Streptomyces deserti $\mathrm{C} 63^{\mathrm{T}}$ & $98.0 \%$ \\
\hline
\end{tabular}

The distribution of the 539 actinobacterial strains from 10 samples is displayed in Figure 2(a) and Table S2. Sample 2 gave the highest diversity (18 genera), followed closely by sample 1 (17 genera), sample 5 (16 genera), sample 4 (13 genera), sample 7 (12 genera), both sample 6 and sample 9 (11 genera), sample 3 (8 genera), sample 10 (4 genera), and sample 8 (2 genera). Among the 10 different media used for isolation of actinobacteria, M7 generated the most successful isolation according to the number and diversity of obtained isolates as shown in Figure 2(b) and Table S3. Totally, 107 actionbacterial strains distributed in 23 genera were obtained from M7. M10 produced the second-highest diversity of isolates (18 genera), and M9 generated the second-highest number of isolates (86 strains). Meanwhile, M1 yielded the lowest number and diversity of isolates (10 strains in 4 genera).

3.2. Novelty of Cultivable Actinobacteria. Among the 539 actinobacterial strains, 11 strains exhibited low $16 \mathrm{~S}$ rRNA gene sequence similarities $(<98.65 \%$, the threshold for differentiating two species) [36] with validly described species based on the results of BLAST search in EzBiocloud (Table 3), which indicated that these isolates could represent novel taxa. The 


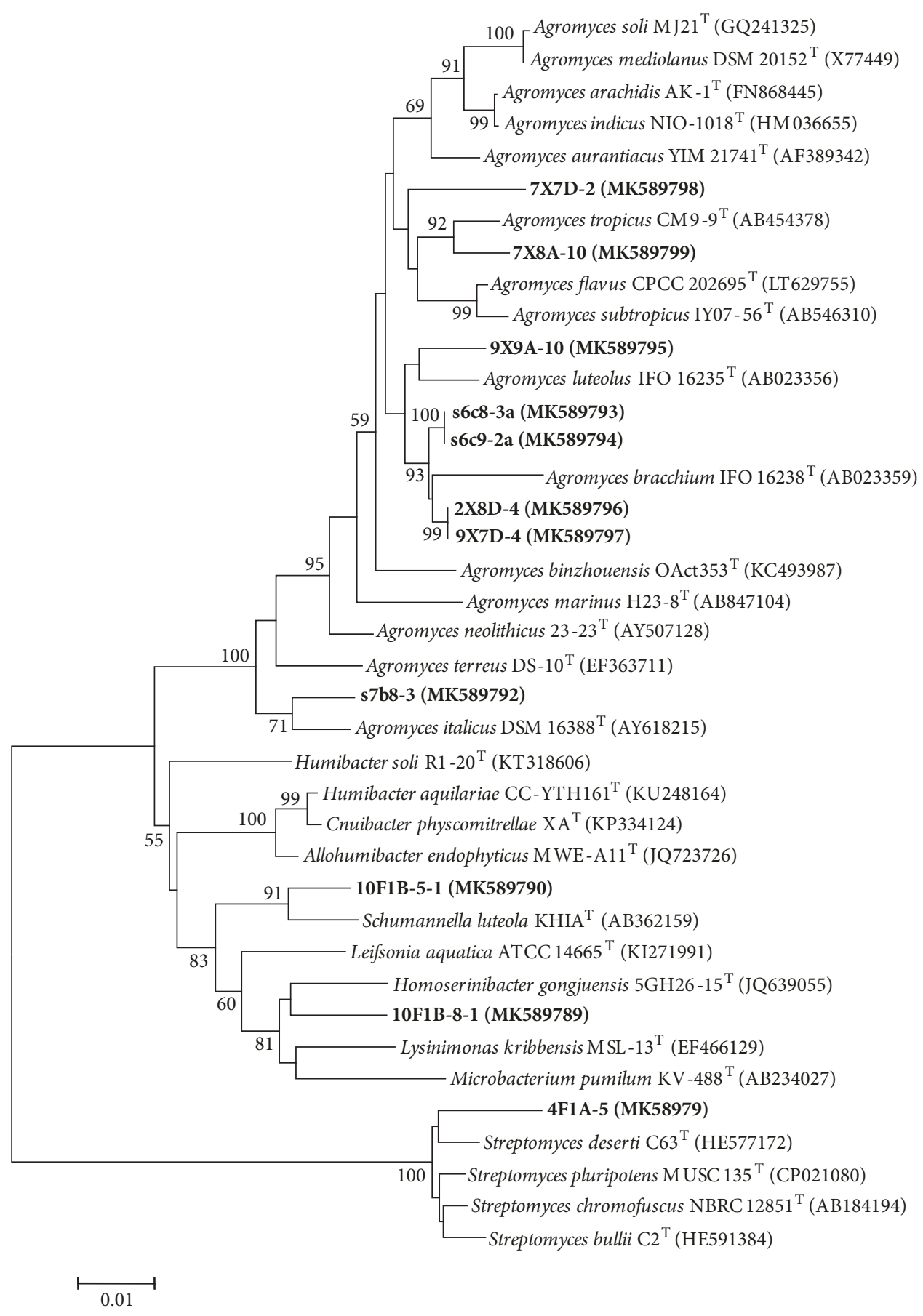

FIGURE 3: Neighbor-joining phylogenetic tree based on almost full-length $16 \mathrm{~S}$ rRNA gene sequences of 11 potential novel strains and their closely related type strains. Numbers at nodes indicate the level of bootstrap support based on 1000 replications (only values $>50 \%$ are shown). Bar, 1 nt substitutions per 100 nt.

phylogenetic tree based on almost full-length $16 \mathrm{~S}$ rRNA gene sequences (Figure 3) showed these potential novel strains were assigned to 4 genera including Agromyces (8 strains), Homoserinibacter (1 strain), Schumannella (1 strain), and Streptomyces (1 strain). These strains will be further identified with a polyphasic approach to determine their taxonomic positions.
3.3. Antibacterial Activity of Actinobacterial Isolates. Among the 115 strains selected for antibacterial assay, 54 strains, affiliated to 23 different genera, showed antagonistic activity against at least one of the indicator bacteria (Table 2). The antibacterial profiles of the 54 strains against "ESKAPE" bacteria are shown in Figure 4. Among them, 37 strains were active against at least one of Gram-positive bacteria and 32 


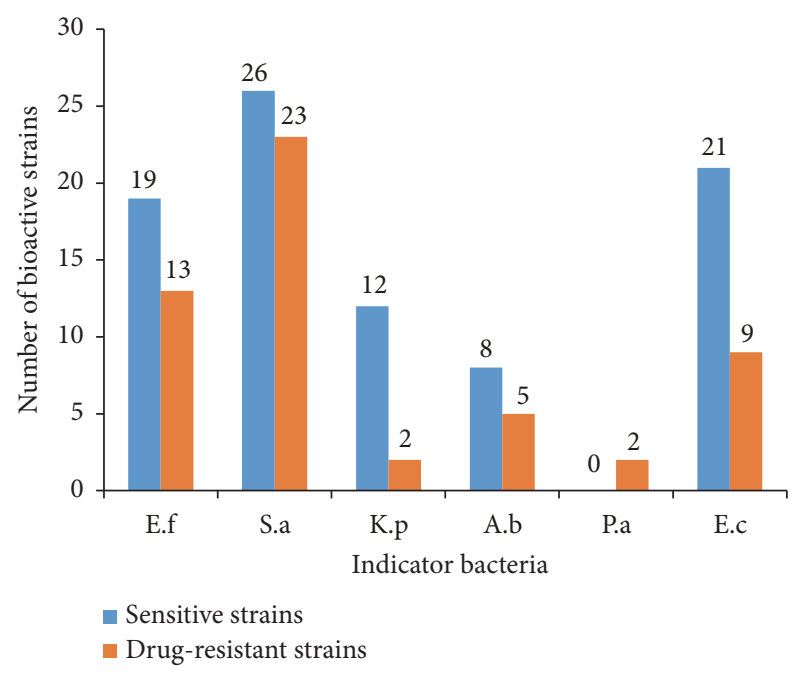

FIGURE 4: The antibacterial profiles of the actinobacteria against "ESKAPE" bacteria (E.f: Enterococcus faecalis; S.a: Staphylococcus aureus; K.p: Klebsiella pneumoniae; A.b: Acinetobacter baumannii; P.a: Pseudomonas aeruginosa; E.c: Escherichia coli).

strains were active against at least one of Gram-negative bacteria; meanwhile, 16 strains exhibited antibacterial activity against both Gram-positive and Gram-negative bacteria.

3.4. Mechanism of Action Determination. Ethyl acetate extracts from the culture broths of 115 strains were screened by the double fluorescent protein reporter system. Five strains, including 3 strains (strains 10X7D-1-3, 7X8A-5, and slb9-3) in genus Streptomyces, 1 strain (strain sld5-4) in genus Micromonospora, and 1 strain (strain s7b4-1) in genus Cellulosimicrobium, induced Katushka2S expression as erythromycin did. Meanwhile, no strain induced SOS-response as levofloxacin did (Figure 5).

\section{Discussion}

Actinobacteria are widely dispersed throughout the mangrove environments [21,37]. Previous studies exhibited 34 actinobacterial genera have ever been isolated from mangrove soil in Futian and Maoweihai [38-47]. In this study, 226 actinobacteria in 29 genera and 313 actinobacteria in 31 genera were isolated from samples collected from Futian and Maoweihai, respectively. Twenty-one genera recovered were shared by both Futian and Maoweihai. The combination of 10 culture media and 10 mangrove soil samples led to the discovery of 39 actinobacterial genera and 11 potential new species, which not only provided more diverse strains for assay, but also demonstrated that it is necessary to use various types of isolation media to increase in the number and diversity of actinobacteria. Mangrove microorganisms especially actinobacteria have been reported to have the ability to produce structurally unique and bioactive natural products $[16,21,48]$. According to the report of Xu et al. [21], about 73 novel compounds have been reported from mangroves originated actinobacteria and among these, 40 new compounds were reported from actinobacteria isolated from the mangrove soil samples only, which shows that actinobacteria from mangrove soil have great advantage to produce new bioactive metabolites.

In the antibacterial assay, 54 strains affiliated to 23 genera, including 26 strains in 11 genera from Futian samples and 28 strains in 15 genera from Maoweihai samples, exhibited inhibitory activities against at least one of "ESKAPE" bacteria as shown in Table S4. These active strains consisted of 20 strains in genus Streptomyces and 34 strains in 22 rare genera. The predominant active strains belong to genus Streptomyces, which is in line with the previous reports $[19,39,49]$. Twenty Streptomycete strains, including a potential new species designated as strain $4 \mathrm{~F} 1 \mathrm{~A}-5$, showed inhibitory activity against at least one of Gram-positive bacteria, and 8 of them also showed activity against at least one of Gram-negative bacteria. As the biggest genus in actinobacteria, Streptomyces contains 848 species and 38 subspecies (http://www.bacterio.net/streptomyces.html), members of genus Streptomyces are well-known as the main sources of antibiotics with diverse biological activities and chemical structures [50], since they usually harbor the large genome size and possess a number of biosynthetic gene clusters that encode multifunctional biosynthetic enzymes $[51,52]$.

Rare actinobacteria also are important sources in the discovery of novel antibiotics [53]. Recently, mangromicins, a group of new secondary metabolites with unique chemical structures, were found from Lechevalieria aerocolonigenes K10-0216 isolated from a mangrove sediment sample by Omura's group [54-56], which further indicated the rare actinobacteria deserve to be studied extensively to find new antibiotics. In the present study, several active strains in 22 rare genera such as Sinomonas, Pseudarthrobacter, Leifsonia, and Gordonia have been rarely studied. Notably, strain 10F1B$8-1$, as a potential new species in rare genus Homoserinibacter, showed broad-spectrum antibacterial activity (Table S4) and is definitely worth studying in priority.

pDualrep2 reporter system is a very sensitive screening model for sorting out antibiotic's mechanisms of action, which can distinguish simultaneously between antibiotics that induce the SOS response due to DNA damage and cause the Katushka2S expression due to ribosome stalling. The existence of ribosome inhibitors such as erythromycin will lead Katushka2S expression, and the existence of inhibitors of DNA biosynthesis such as levofloxacin will lead RFP expression. In this study, screening results indicated 5 strains produced inhibitors of ribosome, but none produced inhibitors of DNA biosynthesis. Taking results of antibacterial activities of the 5 strains into consideration, strains s1b9-3, 10X7D-1-3, and s7b4-1 should be studied by order of importance to find potential antibacterial compounds.

\section{Conclusion}

In our study, the diversity, novelty, and antibacterial activity of cultivable actinobacteria from mangrove soil in Futian and Maoweihai of China were investigated. A total of 539 cultivable actinobacterial strains were identified and affiliated 

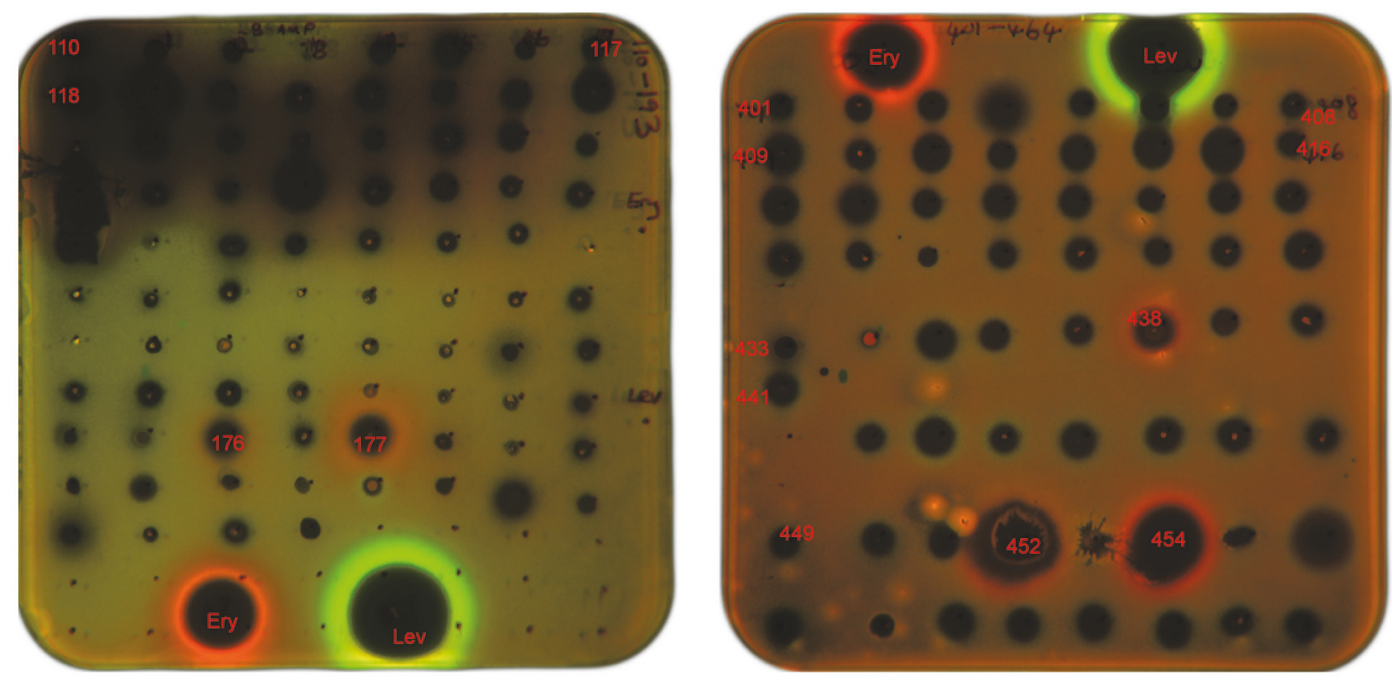

FIGURE 5: Induction of a two-color dual reporter system sensitive to inhibitors of the ribosome progression or inhibitors of DNA replication, respectively. Spots of erythromycin (Ery), levofloxacin (Lev), and tested samples were placed on the surface of an agar plate containing E. coli tolC cells transformed with the pDualrep2 reporter plasmid. Shown is the fluorescence of the lawn of E. coli cells scanned at 553/574 nm (green pseudocolor) for RFP fluorescence and 588/633 nm (red pseudocolor) for Katushka2S fluorescence. Induction of Katushka2S expression is triggered by translation inhibitors, while RFP is upregulated by induction of DNA damage SOS response. 176: 10X7D-1-3; 177: 7X8A-5; 438: s1d5-4; 452: s7b4-1; 454: s1b9-3.

to 39 genera in 18 families of 8 orders. Eleven strains were considered as potential new taxa. The antibacterial assays showed 54 strains in 23 genera had antagonistic activities against at least one of "ESKAPE" bacteria, and the screening results based on pDualrep2 reporter system indicated the cultural broth of 5 strains could cause ribosome stalling as erythromycin did. Comprehensive analyses of all results in present study reveal that streptomycetes and rare actinobacteria isolated from mangrove soil are valuable sources to find new antibiotics. Notably, it seems that culture broths of streptomyces more frequently exhibit inhibitory activities against Gram-positive bacteria such as E. faecium and $S$. aureus than against Gram-negative bacteria such as $P$. aeruginosa. Sensitive and reliable screening model based on mechanism of action can accelerate the selection of target strains for further chemical studies.

\section{Data Availability}

The data used to support the findings of this study are available from the corresponding authors upon request.

\section{Conflicts of Interest}

The authors declare no conflicts of interest.

\section{Acknowledgments}

This research was partly supported by the Drug Innovation Major Project of China (Grant No. 2018ZX09711001-007001), PUMC Youth Fund (Grant No. 2017350022), CAMS Innovation Fund for Medical Sciences (Grant No. CAMS 2017-I2M-1-012), Russian Science Foundation (Grant No.
18-44-04005), and National Natural Sciences Foundation of China (Grant No. 81621064; 81361138020; 81460537).

\section{Supplementary Materials}

Table S1: Composition of ten different media used for isolation of actinobacteria from mangrove soil in Futian and Maoweihai. Table S2: Information on genera distribution of actinobacterial isolates from different samples. Table S3: Information on genera distribution of actinobacterial isolates recovered from the different culture media. Table S4: Antibacterial activity of 54 actinobacterial strains from mangrove soil in Futian and Maoweihai. (Supplementary Materials)

\section{References}

[1] J. J. Hug, C. D. Bader, M. Remškar, K. Cirnski, and R. Müller, "Concepts and methods to access novel antibiotics from actinomycetes," Antibiotics, vol. 7, no. 2, article 44, 2018.

[2] M. Gajdács, "The concept of an ideal antibiotic: implications for drug design," Molecules, vol. 24, no. 5, article 892, 2019.

[3] World Health Organization, Global priority list of antibioticresistant bacteria to guide research, discover, and development of new antibiotics, 2017.

[4] E. Tacconelli, E. Carrara, A. Savoldi et al., "Discovery, research, and development of new antibiotics: the WHO priority list of antibiotic-resistant bacteria and tuberculosis," The Lancet Infectious Diseases, vol. 18, no. 3, pp. 318-327, 2018.

[5] A. Cumsille, A. Undabarrena, V. González, F. Claverías, C. Rojas, and B. Cámara, "Biodiversity of actinobacteria from the South Pacific and the assessment of Streptomyces chemical diversity with metabolic profiling," Marine Drugs, vol. 15, no. 9, article 286, 2017. 
[6] S. Sangkanu, V. Rukachaisirikul, C. Suriyachadkun, and S. Phongpaichit, "Evaluation of antibacterial potential of mangrove sediment-derived actinomycetes," Microbial Pathogenesis, vol. 112, pp. 303-312, 2017.

[7] S. Qin, W.-J. Li, S. G. Dastager, and W. N. Hozzein, "Editorial: actinobacteria in special and extreme habitats: diversity, function roles, and environmental adaptations," Frontiers in Microbiology, vol. 7, article 1415, 2016.

[8] L. Trenozhnikova and A. Azizan, "Discovery of actinomycetes from extreme environments with potential to produce novel antibiotics," Central Asian Journal of Global Health, vol. 7, no. 1, article 337, 2018.

[9] L. Carro, J. F. Castro, V. Razmilic et al., "Uncovering the potential of novel micromonosporae isolated from an extreme hyper-arid Atacama Desert soil," Scientific Reports, vol. 9, no. 1, article 4678, 2019.

[10] B.-K. Choi, S.-Y. Park, D.-K. Choi et al., "Streptoglycerides A-D with a Rare 6/5/5 tricyclic ring skeleton from a marine actinomycete Streptomyces species," Organic Letters, vol. 20, no. 19, pp. 6037-6040, 2018.

[11] J. W. Law, H. Ser, N. Ab Mutalib et al., "Streptomyces monashensis sp. nov., a novel mangrove soil actinobacterium from East Malaysia with antioxidative potential," Scientific Reports, vol. 9, no. 1, article 3056, 2019.

[12] Z. E. Wilson and M. A. Brimble, "Molecules derived from the extremes of life," Natural Product Reports, vol. 26, no. 1, pp. 4471, 2009.

[13] J. G. S. P. Kumar, A. Gomathi, K. M. Gothandam, and V. Vasconcelos, "Bioactivity assessment of Indian origin-mangrove actinobacteria against Candida albicans," Marine Drugs, vol. 16, no. 2, article 60, 2018.

[14] T. Li, T. Ding, and J. Li, "Medicinal purposes: bioactive metabolites from marine-derived organisms," Mini-Reviews in Medicinal Chemistry, vol. 19, no. 2, pp. 138-164, 2019.

[15] M. E. Rateb, R. Ebel, and M. Jaspars, "Natural product diversity of actinobacteria in the Atacama Desert," Antonie van Leeuwenhoek-Journal of Microbiology, vol. 111, no. 8, pp. 14671477, 2018.

[16] A.-S. Azman, I. Othman, S. S. Velu, K.-G. Chan, and L.-H. Lee, "Mangrove rare actinobacteria: taxonomy, natural compound, and discovery of bioactivity," Frontiers in Microbiology, vol. 6, article 856, 2015.

[17] C. Giri, E. Ochieng, L. L. Tieszen et al., "Status and distribution of mangrove forests of the world using earth observation satellite data," Global Ecology and Biogeography, vol. 20, no. 1, pp. 154-159, 2011.

[18] P. Manivasagan, J. Venkatesan, K. Sivakumar, and S.-K. Kim, "Pharmaceutically active secondary metabolites of marine actinobacteria," Microbiological Research, vol. 169, no. 4, pp. 262278, 2014.

[19] K. Hong, A. Gao, Q. Xie et al., "Actinomycetes for marine drug discovery isolated from mangrove soils and plants in China," Marine Drugs, vol. 7, no. 1, pp. 24-44, 2009.

[20] H. Thatoi, B. C. Behera, R. R. Mishra, and S. K. Dutta, "Biodiversity and biotechnological potential of microorganisms from mangrove ecosystems: a review," Annals of Microbiology, vol. 63, no. 1, pp. 1-19, 2013.

[21] D.-B. Xu, W.-W. Ye, Y. Han, Z.-X. Deng, and K. Hong, "Natural products from mangrove actinomycetes," Marine Drugs, vol. 12, no. 5, pp. 2590-2613, 2014.
[22] Z.-K. Jiang, L. Tuo, D.-L. Huang et al., "Diversity, novelty, and antimicrobial activity of endophytic actinobacteria from mangrove plants in Beilun Estuary National Nature Reserve of Guangxi, China," Frontiers in Microbiology, vol. 9, article 868, 2018.

[23] X. Dan, B. Liao, Z. Wu et al., "Resources, conservation status and main threats of mangrove wetlands in China," Ecology and Environmental Sciences, vol. 25, no. 7, pp. 1237-1243, 2016.

[24] B. Gong, S. Chen, W. Lan et al., "Antibacterial and antitumor potential of actinomycetes isolated from mangrove soil in the Maowei Sea of the southern coast of China," Iranian Journal of Pharmaceutical Research, vol. 17, no. 4, pp. 1339-1346, 2018.

[25] X. J. Li, Y. Wu, W. M. Zhang et al., "Biodiversity and antimicrobial activity of culturable actinobacteria isolated from Jiuliancheng Nur in Hebei Province," Microbiology China, vol. 43, no. 7, pp. 1473-1484, 2016.

[26] W.-J. Li, P. Xu, P. Schumann et al., "Georgenia ruanii sp. nov., a novel actinobacterium isolated from forest soil in Yunnan (China) and emended description of the genus Georgenia," International Journal of Systematic and Evolutionary Microbiology, vol. 57, no. 7, pp. 1424-1428, 2007.

[27] E. F. DeLong, "Archaea in coastal marine environments," Proceedings of the National Acadamy of Sciences of the United States of America, vol. 89, no. 12, pp. 5685-5689, 1992.

[28] S.-H. Yoon, S.-M. Ha, S. Kwon et al., "Introducing EzBioCloud: a taxonomically united database of $16 \mathrm{~S}$ rRNA gene sequences and whole-genome assemblies," International Journal of Systematic and Evolutionary Microbiology, vol. 67, no. 5, pp. 1613-1617, 2017.

[29] S. F. Altschul, W. Gish, W. Miller, E. W. Myers, and D. J. Lipman, "Basic local alignment search tool," Journal of Molecular Biology, vol. 215, no. 3, pp. 403-410, 1990.

[30] S. Kumar, G. Stecher, and K. Tamura, "MEGA7: molecular evolutionary genetics analysis version 7.0 for bigger datasets," Molecular Biology and Evolution, vol. 33, no. 7, pp. 1870-1874, 2016.

[31] N. Saitou and M. Nei, "The neighbor-joining method: a new method for reconstructing phylogenetic trees," Molecular Biology and Evolution, vol. 4, no. 4, pp. 406-425, 1987.

[32] M. Kimura, "A simple method for estimating evolutionary rates of base substitutions through comparative studies of nucleotide sequences," Journal of Molecular Evolution, vol. 16, no. 2, pp. 111120,1980

[33] J. Felsenstein, "Confidence limits on phylogenies: an approach using the bootstrap," Evolution, vol. 39, no. 4, pp. 783-791, 1985.

[34] D. M. Isaacson and J. Kirschbaum, "Assays of antimicrobial substances," in Manual of Industrial Microbiology and Biotechnology, A. L. Demain and N. A. Solomon, Eds., pp. 410-435, American Society for Microbiology, Washington, DC, USA, 1986.

[35] I. A. Osterman, E. S. Komarova, D. I. Shiryaev et al., "Sorting out antibiotics' mechanisms of action: a double fluorescent protein reporter for high throughput screening of ribosome and DNA biosynthesis inhibitors," Antimicrobial Agents and Chemotherapy, vol. 60, no. 12, pp. 7481-7489, 2016.

[36] M. Kim, H.-S. Oh, S.-C. Park, and J. Chun, "Towards a taxonomic coherence between average nucleotide identity and $16 \mathrm{~S}$ rRNA gene sequence similarity for species demarcation of prokaryotes," International Journal of Systematic and Evolutionary Microbiology, vol. 64, no. 2, pp. 346-351, 2014. 
[37] C. H. Sun, F. N. Li, Z. Cai et al., "Brief introduction of mangrove researches including drug discovery granted by National Natural Science Foundation of China from 1986 to 2016," Chinese Journal of Antibiotics, vol. 42, no. 4, pp. 241-248, 2017.

[38] X. L. Jiang, X. T. Liang, and J. M. Cao, "Selection of antibiotic actinomyces from mangrove forest ecosystem in Futian, Shenzhen," Periodical of Ocean University of China, vol. 36, no. 4, pp. 601-605, 2006.

[39] K. Hong, "Actinomycetes from mangrove and their secondary metabolites," Acta Microbiologica Sinica, vol. 53, no. 11, pp. 11311141, 2013.

[40] X. Lei, Z. Shen, K. Hong et al., "Isolate rare actinomycetes from environment of torrid zone," Biotechnology Bulletin, vol. 22, no. 1, pp. 454-463, 2006.

[41] Z.-L. Liao, S.-K. Tang, L. Guo et al., "Verrucosispora lutea sp. nov., isolated from a mangrove sediment sample," International Journal of Systematic and Evolutionary Microbiology, vol. 59, no. 9, pp. 2269-2273, 2009.

[42] H. Hu, H.-P. Lin, Q. Xie et al., "Streptomyces shenzhenensis sp. nov., a novel actinomycete isolated from mangrove sediment," Antonie van Leeuwenhoek-Journal of Microbiology, vol. 100, no. 4, pp. 631-637, 2011.

[43] D. Hu, C. Gao, C. Sun et al., "Genome-guided and mass spectrometry investigation of natural products produced by a potential new actinobacterial strain isolated from a mangrove ecosystem in Futian, Shenzhen, China," Scientific Reports, vol. 9, no. 1, article 823, 2019.

[44] D. Yan, W. Wang, M. Li et al., "Diversity of rhizospheric bacteria and its inhibition activity from Sonneratia apetala in Maowei Sea," Journal of Southern Agriculture, vol. 49, no. 6, pp. 10951101, 2018.

[45] J. Ye, H. Zheng, Y. Wu et al., "Diversity and antimicrobial activity of actinobacteria isolated from mangrove rhizosphere soil in the Maowei Sea of Guangxi," Journal of Pathogen Biology, vol. 13, no. 11, pp. 1221-1226, 2018.

[46] S. B. Shi, L. F. Yang, M. G. Jiang et al., "A comparison of actinomycetes isolation medium with samples from mangrove habitats in Maowei Sea, Guangxi Beibu Gulf," Microbiology China, vol. 45, pp. 2331-2340, 2018.

[47] J. Wu, S. Wu, Z. Li et al., "Biodiversity and screening of culturable actinobacteria against Fusarium oxysporum isolated from mangrove soil in Maowei Sea," Chinese Journal of Antibiotics, vol. 42, no. 4, pp. 294-301, 2017.

[48] Z. Xu, Z. Feng, and J. Xu, "Research advances on antimicrobial activities of microbes derived from mangrove," Chinese Journal of Antibiotics, vol. 42, no. 4, pp. 241-254, 2017.

[49] J. Bérdy, "Bioactive microbial metabolites," The Journal of Antibiotics, vol. 58, no. 1, pp. 1-26, 2005.

[50] M. V. Arasu, V. Duraipandiyan, P. Agastian, and S. Ignacimuthu, "Antimicrobial activity of Streptomyces spp. ERI-26 recovered from Western Ghats of Tamil Nadu," Journal de Mycologie Médicale, vol. 18, no. 3, pp. 147-153, 2008.

[51] C. Rückert, A. Albersmeier, T. Busche et al., "Complete genome sequence of Streptomyces lividans TK24," Journal of Biotechnology, vol. 199, pp. 21-22, 2015.

[52] M. J. Bibb, "Regulation of secondary metabolism in streptomycetes," Current Opinion in Microbiology, vol. 8, no. 2, pp. 208215, 2005.

[53] K. Tiwari and R. K. Gupta, "Rare actinomycetes: a potential storehouse for novel antibiotics," Critical Reviews in Biotechnology, vol. 32, no. 2, pp. 108-132, 2012.
[54] T. Nakashima, Y. Kamiya, M. Iwatsuki, Y. Takahashi, and S. Omura, "Mangromicins, six new anti-oxidative agents isolated from a culture broth of the actinomycete, Lechevalieria aerocolonigenes K10-0216," The Journal of Antibiotics, vol. 67, no. 7, pp. 533-539, 2014.

[55] T. Nakashima, M. Iwatsuki, J. Ochiai et al., "Mangromicins A and B: structure and antitrypanosomal activity of two new cyclopentadecane compounds from Lechevalieria aerocolonigenes K10-0216," The Journal of Antibiotics, vol. 67, no. 3, pp. 253260, 2014.

[56] T. Nakashima, Y. Kamiya, M. Iwatsuki et al., "Mangromicin C, a new analog of mangromicin," The Journal of Antibiotics, vol. 68, no. 3, pp. 220-222, 2015. 


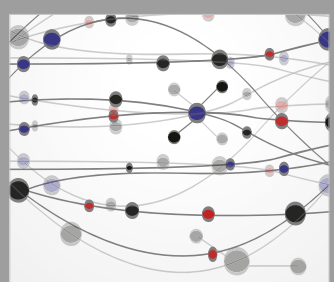

The Scientific World Journal
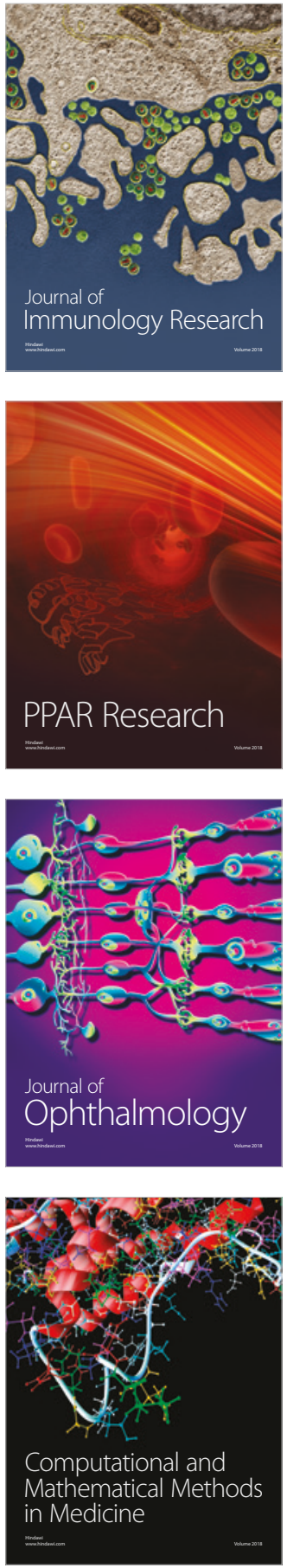

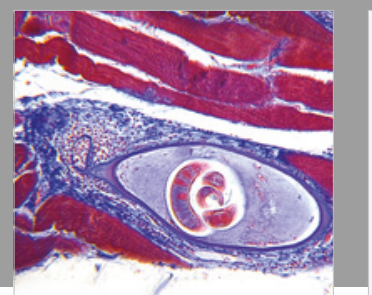

Gastroenterology Research and Practice

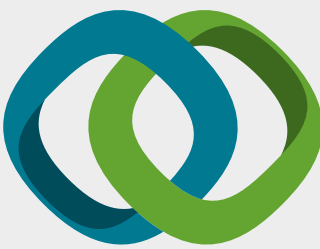

\section{Hindawi}

Submit your manuscripts at

www.hindawi.com
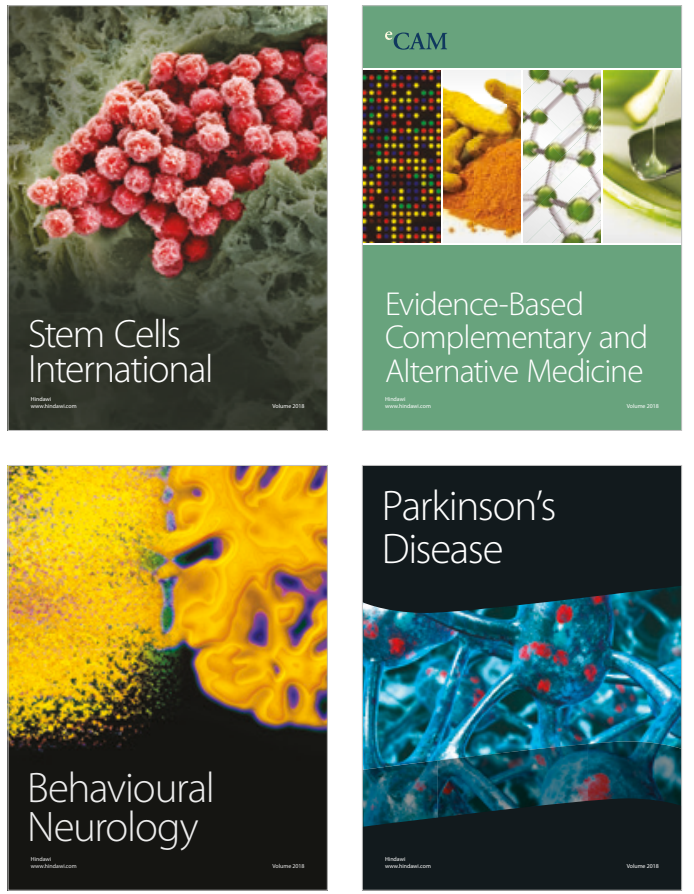

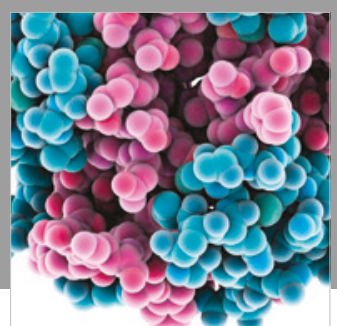

ournal of

Diabetes Research

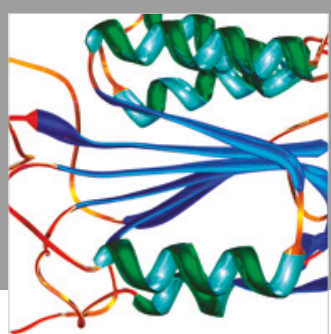

Disease Markers
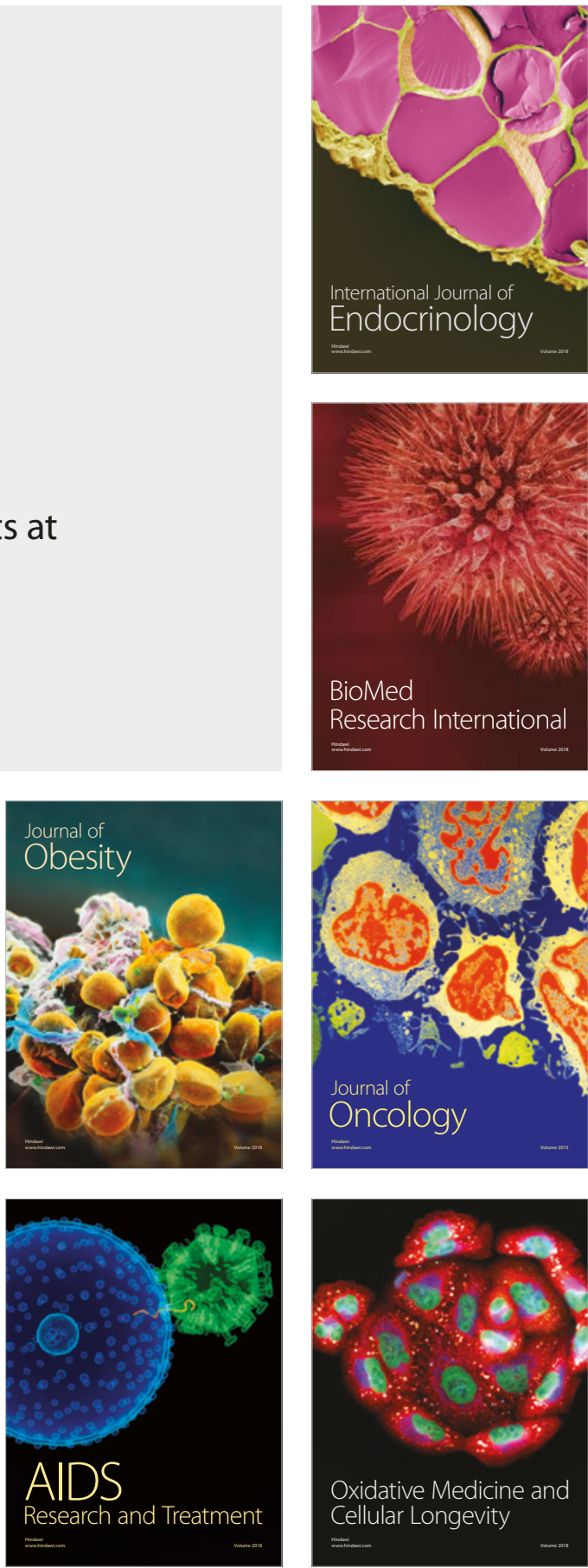